
и околоносовых пазух у детей

Контактная информация:

Васильева Надежда Игоревна, врач-отоларинголог высшей категории Российской детской клинической больницы Адрес: 117997, Москва, Ленинский проспект, д. 117, тел.: (495) 936-93-24, e-mail: Vasilieva_n_i@rdkb.ru Статья поступила: 24.09.2012 г., принята к печати: 05.10.2012 г.

В статье говорится о применении местной антибактериальной терапии при наиболее часто встречающихся в детском возрасте острых и хронических воспалительных заболеваниях носоглотки, полости носа и околоносовых пазух. Проанализированы преимущества топического способа этиотропной терапии при указанной патологии, обсуждаются показания к назначению антибактериальных препаратов и наиболее часто допускаемые в этом случае ошибки. Обсуждаются актуальные аспекты этиологии, отличительные признаки вирусных и бактериальных воспалительных заболеваний носоглотки, полости носа и околоносовых пазух.

Ключевые слова: дети, острые респираторные инфекции, риносинусит, аденоидные вегетации, аденоидит, местная антибактериальная терапия.

(Вопросы современной педиатрии. 2012; 11 (5): 142-148)

Осенью, в сезон разгара острых респираторных инфекций (ОРИ), весьма актуален вопрос тактики лечения как непосредственно самих инфекционных заболеваний у детей, так и сопряженной с ними воспалительной патологии ЛОР-органов.

Одним из наиболее сложных вопросов для педиатров и оториноларингологов остается необходимость назначения при ОРИ антибактериальных препаратов, которые, к сожалению, в силу различных причин, до сих пор назначают необоснованно часто [1]. Схожесть симптомов вирусных и бактериально обусловленных воспалительных процессов ЛОР-органов (преимущественно на ранних стадиях заболевания), ограниченность диагностических возможностей для идентификации возбудителя, особенно на амбулаторном этапе лечения, популярность ряда лекарственных средств среди родителей из-за постоянной их рекламы в средствах массовой информации и склонность врачей к агрессивной многокомпонентной терапии уже долгое время значительно осложняют решение данной проблемы [1-7].

Хорошо известно, что до 90\% острых респираторных болезней вызывают вирусы, при этом частота необоснованного применения системных антибиотиков у детей высока практически во всех странах мира $[2,4]$. В России этот показатель колеблется в пределах 60-80\% [2, 3]. По данным Л.С. Страчунского, в условиях поликлиники

N.I. Vasil'eva

Russian Children Clinical Hospital, Moscow, Russian Federation

\title{
The usage of topical antibacterial drugs in treatment of inflammatory diseases of the nose, the nasopharynx and the paranasal sinuses in children
}

The article deals with the issues of topical antibacterial treatment of the most common pediatric acute and chronic inflammatory diseases of the nasopharynx, the nasal cavity and the paranasal sinuses. The author analyzed the benefits of the topical etiotropic therapy of such conditions, the indications for the antibacterial drugs usage and the most common mistakes. The current issues of etiology, as well as the special features of viral and bacterial inflammatory diseases of the nasopharynx, the nasal cavity and the paranasal sinuses are discussed.

Key words: children, acute respiratory infections, rhinosinusitis, adenoid vegetations, adenoiditis, topical antibacterial treatment. (Voprosy sovremennoi pediatrii - Current Pediatrics. 2012; 11 (5): 142-148) 
необоснованно получают антибиотики до 48\% больных детей с острыми респираторными вирусными инфекциями (ОРВИ), хотя действительные показания к их назначению имеются лишь у 8-10\% [8].

Результаты ряда исследований убедительно свидетельствуют о том, что применение системных антибиотиков при ОРИ не только неоправданно, но и порой небезопасно [2-4, 9]. Анализ последних зарубежных работ показывает, что назначение системных антибиотиков при ринитах, риносинуситах, ринофарингитах у детей при недоказанной бактериальной природе патологического состояния не приводит к ускорению купирования основных симптомов заболевания [4, 9-12]. Кроме того, существуют многочисленные данные о том, что раннее необоснованное назначение системных антибиотиков не предупреждает развитие таких осложнений ОРИ, как пневмония и острый средний отит $[1-3,8]$. Таким образом, детям с неотягощенным анамнезом при ОРИ антибиотики назначать не следует, поскольку они не ускоряют выздоровление и не предотвращают развитие осложнений [1, 2].

К наиболее распространенным побочным реакциям при системной антибактериальной терапии инфекционновоспалительных заболеваний у детей относят:

- токсические реакции с поражением различных органов и систем (вестибулярного и слухового нерва, почек, печени, периферической нервной системы, желудочно-кишечного тракта, системы кроветворения);

- аллергические реакции;

- формирование антибиотикорезистентности возбудителей [2, 4, 8, 9, 13].

Аллергические реакции на антибиотики возникают у детей достаточно редко [8]. Однако, по результатам наблюдений и исследований профессора В.К. Таточенко, такие реакции чаще всего развиваются как раз у детей, которым антибиотик был назначен при ОРИ вирусной природы без должных показаний. Это связано, по-видимому, с тем, что бактериальная инфекция вызывает определенные изменения клеточного обмена на уровне медиаторов, которые препятствуют манифестации аллергических проявлений. Таких сдвигов не наблюдается при вирусных инвазиях, что потенцирует аллергическую настроенность детского организма, усиливаемую, в свою очередь, рядом антибактериальных препаратов [2].

Кроме того, продемонстрирована возможность «Вмешательства" частого курсового применения системных антибиотиков у детей первых лет жизни с ОРВИ в процесс своевременного созревания полноценной иммунной защиты. При этом наблюдается задержка преобладания несовершенного Т-хелперного ответа 2-го типа, что предрасполагает ребенка к повторным вирусным заболеваниям [2, 14].

Спектр применяемых антибактериальных препаратов в лечении воспалительных заболеваний лоР-органов у детей достаточно велик. Порой сложно разграничить ситуации, когда оправдано применение аминопенициллинов, а когда следует выбрать их ингибиторозащищенные формы - цефалоспорины или макролиды. Не всегда легким бывает решение о возможности ограничиться только местной антибактериальной терапией или же прибегнуть к системному способу введения, а возможно и к их комбинации $[4,8]$. Однако существуют определенные общие тактические правила в назначении антибактериальной терапии детям с лоР-патологией, основанные на многолетнем опыте отечественных практикующих специалистов и, конечно, мировых многоцентровых исследований. Эти правила направлены на минимизацию частоты развития побочных эффектов вследствие неоправданного применения системных антибиотиков в повседневной практике педиатров, оториноларингологов, пульмонологов [8].

К главным целям антибактериальной терапии, показанной ребенку с воспалительной ЛоР-патологией, относят следующие.

- Эрадикацию бактериального возбудителя. Оптимальным вариантом, как хорошо известно, является выбор антибиотика в соответствии с результатом микробиологического исследования материала из очага воспаления [1, 4]. Однако его проведение в рутинных случаях острых риносинуситов, фарингитов, аденоидитов и при обострениях их хронических форм у детей, особенно в амбулаторных условиях, не считается необходимым. Кроме этого, результаты исследования получают отсроченно. Дифференциальную диагностику между вирусной и бактериальной формой заболеваний проводят на основании клинических данных [3, 4, 9, 12]. Проблема заключается в том, что клинические признаки острого бактериального и затянувшегося вирусного процесса очень похожи, что часто приводит к гипердиагностике первого. Как показывает практика, правильный диагноз бактериальной причины воспалительного процесса в условиях первичной медицинской помощи ставят не более чем в $50 \%$ случаев $[12,13]$.

- Предотвращение осложнений, ассоциированных с активацией патогенной или условно-патогенной микрофлоры в очаге воспаления [4, 8].

- Уменьшение степени тяжести клинической симптоматики $[4,8]$.

- Сокращение риска хронизации воспалительного процесса. Применение антибактериальной терапии с этой целью при остром бактериальном процессе в детском возрасте целесообразно, однако не является первичной и главной задачей, так как причины хронического течения воспалительных заболеваний лоР-органов у детей многообразны, и затрагивают в первую очередь иммунологические нарушения $[2,4,10]$.

Зачастую основными причинами неэффективности назначенной системной антибактериальной терапии (в случае неосложненного вирусного заболевания, протекающего с клинической картиной, например, риносинусита или ринофарингита) является неоправданно раннее начало лечения - до момента присоединения бактериальной инфекции. Это может привести к необходимости смены антибактериального препарата в случае действительного развития осложнений, что является риском развития полирезистентности микробных возбудителей, аллергизации ребенка и провоцирования иммуносупрессии [3, 4, 11]. 
К сожалению, многие родители придерживаются точки зрения, что хронические воспалительные заболевания органов носоглотки у ребенка, сопровождающиеся нарушением носового дыхания, ринореей, частыми эпизодами ОРИ, не являются поводом для обращения к врачу и тем более - для лечения, расценивая их как возрастные нормальные явления, которые должны пройти со временем сами собой. До 35\% родителей отказываются применять антибактерильные препараты системного действия при ЛОР-патологии $[9,15]$. Часто родители категорически не приемлют возможности назначения своим детям назальных глюкокортикоидов (до 32\%) [12, 15], при этом они стараются найти альтернативные пути лечения, например, прибегая к гомеопатии, неоправданно считая препараты данного ряда не менее эффективными, но абсолютно безопасными.

Учитывая возможные отрицательные аспекты при назначении системных антибиотиков, особенно у детей первых лет жизни, трудности в решении вопроса о необходимости системной антибактериальной терапии, а также немаловажную достаточно низкую комплаентность родителей в таких случаях, необходимо указать на актуальность применения методов местного антибактериального лечения воспалительной лоР-патологии у детей. Это стало возможным и, что особенно важно (согласно данным доказательной медицины последних лет), безопасным и эффективным благодаря появлению антибактериальных препаратов топического действия в виде назальных спреев. К ним, в частности, относятся лекарственные препараты Полидекса с фенилэфрином и Изофра компании "Лаборатория Бушара-Рекордати" (Франция) [16-20].

Основу назального спрея Изофра составляет антибиотик аминогликозидного ряда топического бактерицидного действия фрамицетин, содержание которого в 1 мл препарата составляет 8000 Ед. В состав Полидексы с фенилэфрином входят 2 антибиотика: неомицин (также группа аминогликозидов), 6500 Ед, и полимиксин В, 10000 Ед, - полипептидный антибиотик из группы полимиксинов [21].

Как известно, аминогликозиды высокоактивны в отношении большинства грамотрицательных и грамположительных микроорганизмов - возбудителей инфекций верхних отделов респираторного тракта. Полимиксин В отличается преимущественной активностью в отношении грамотрицательных микроорганизмов, в особенности синегнойной и гемофильной палочки, клебсиеллы. Сочетание неомицина с полимиксином В полностью перекрывает весь спектр микроорганизмов, встречающихся при хронических воспалительных процессах в носоглотке, когда высока вероятность преобладания агрессивной грамотрицательной флоры и анаэробных возбудителей [8]. Однако антибактериальные препараты системного действия указанных групп обладают побочным ототоксическим эффектом, а это делает невозможным использование их антимикробного потенциала при бактериальных инфекциях полости носа, носоглотки и околоносовых пазух у детей $[8,21]$.

Указанных побочных эффектов можно не опасаться при местном введении данных антибактериальных пре- паратов, Т. к., согласно результатам клинических исследований, уровень их системной абсорбции при топическом использовании крайне низок $[13,16,21]$. Кроме этого, количество входящих в состав данных назальных спреев антибиотиков, поступающих при правильном использовании препаратов за сут в полость носа, в несколько раз ниже их установленных максимальных допустимых доз для топического применения [16, 21].

Типичной ситуацией является негативное отношение ребенка раннего возраста к необходимости одновременного использования нескольких назальных препаратов местного действия. Именно поэтому одним из привлекательных направлений в применении лекарственных средств топического действия у детей при лоР-патологии является использование многокомпонентных препаратов, сочетающих основные эффекты, требуемые для адекватного местного лечения: антимикробное, противовоспалительное, местное гипосенсибилизирующее, а также сосудосуживающее действие. При этом такой препарат должен, конечно же, быть безопасен для ребенка. Таким требованиям полностью удовлетворяет комбинированный спрей для носа с фенилэфрином $[13,16,21]$. Необходимо отметить, что это единственный препарат топического действия на отечественном рынке, сочетающий в себе антимикробное и сосудосуживающее действие [21].

Входящий в состав препарата дексаметазон в дозе 0,25 мг на 1 мл раствора обеспечивает противовоспалительный и гипосенсибилизирующий эффект, влияя таким образом на важнейшие патогенетические звенья воспалительного процесса. Деконгестант фенилэфрин в дозе 2,5 мг на 1 мл оказывает мягкое сосудосуживающее действие, не вызывая пересушивания слизистой оболочки полости носа и не нарушая функции мерцательного эпителия. Указанные дозы активных веществ в пересчете на суточное количество существенно ниже их допустимых максимальных значений, что в случае фенилэфрина минимизирует возможность развития медикаментозного ринита и привыкания к препарату [21].

Показаниями к назначению указанных препаратов в первую очередь являются наиболее часто встречаемые в детском возрасте воспалительные заболевания лОРорганов [6, 21].

Известно, что структура лоР-патологии несколько меняется по мере роста и развития детского организма $[6,7]$. С первых лет жизни вплоть до раннего школьного возраста именно гипертрофия аденоидных вегетаций и аденоидиты занимают лидирующее положение в структуре заболеваний лОР-органов у детей $[6,7]$. К сожалению, данные многочисленных исследований во всем мире указывают на отчетливый рост частоты встречаемости этой патологии детского возраста. Около 50 лет назад менее 15\% детей имели изменения со стороны глоточной миндалины, тогда как в последние годы эта цифра в среднем составляет 56\% [6, 18].

По данным российских статистических исследований, гипертрофию глоточной миндалины и хронический аденоидит диагностируют у $45 \%$ детей дошкольного возраста. Причем среди всех случаев патологии со стороны аденоидных вегетаций аденоидит встречается у 32,8- 
43,8\% больных [6, 7]. Существенно выше эти показатели в группе часто и длительно болеющих детей: гипертрофию глоточной миндалины II и III стадии имеют до 87,3\% из них, при этом встречаемость хронического аденоидита существенно не отличается от показателей в общей группе детей и составляет $36,1 \%[7,15,18]$.

Такая высокая подверженность детей заболеваниям органов лимфоглоточного кольца обусловлена несформированностью и определенными периодами недостаточной эффективности мукозального иммунитета. Эта же причина лежит в основе рецидивирующих острых респираторных болезней, риносинуситов. В каждом из условно выделяемых периодов есть иммунные особенности, определяющие подверженность детского организма инвазии определенных возбудителей, а также поражению определенных ЛОР-органов [10, 22, 23].

Первым критическим периодом развития иммунологической защиты считается период новорожденности, когда она носит пассивный характер за счет материнских антител, а система неспецифической защиты еще не развита. Во втором критическом периоде (4-6 мес жизни) происходит ослабление пассивного гуморального иммунитета, начинается развитие первичного незрелого иммунного ответа с синтезом антител класса М, не оставляющим иммунологической памяти. Третий критический период (2-4-й годы жизни) характеризуется существенной незрелостью местного мукозального иммунитета, В т. ч. за счет недостаточной продукции секреторного иммуноглобулина (Ig) А. В этом возрасте у детей все еще сохраняется Т2-хелперный тип иммунного ответа с низким уровнем синтеза антител класса G. Отмечаются крайне низкие показатели выработки лимфоэпителиальными тканями носоглотки интерферона $\alpha$ и $\gamma$ [10].

Особенности иммунной системы описанных 3 критических периодов жизни ребенка характеризуются низкой резистентностью по отношению к вирусной инвазии и условно-патогенной грамположительной микрофлоре. Среди бактериальных возбудителей патологии лоРорганов часто превалирует стафилококк. Воспалительные процессы могут носить рецидивирующий характер, поскольку бактерии, вызывающие их, не индуцируют гуморальный иммунный ответ. Небные и глоточная миндалины на фоне низкой способности лимфоидной ткани к синтезу полноценных антител отвечают на бактериальную и рецидивирующую вирусную инфекцию выраженной гиперплазией, длительно сохраняющейся после купирования острого воспалительного процесса. Кроме того, у детей дошкольного возраста глоточная миндалина более активно реагирует на антигенную стимуляцию, т.к. покрыта реснитчатым цилиндрическим эпителием $[10,22,24]$.

Особенностями четвертого критического периода, приходящегося на 6-7-й годы жизни, являются сохраняющиеся сниженные концентрации IgA в ткани миндалин и значительно повышенное содержание IgE, что создает предпосылки для развития атопических болезней. Подростковый возраст - пятый критический период иммунологической защиты. В это время снижается масса лимфоидных органов, подавляется Т-клеточное звено иммунитета, в то время как гуморальное зве- но стимулируется половыми гормонами. В связи с этим вновь возрастает роль стафилококков, анаэробов, энтеробактерий, условно-патогенной и атипичной микрофлоры в патогенезе воспалительных заболеваний верхних дыхательных путей [10, 22].

Подходы к тактике ведения детей с аденоидными вегетациями и аденоидитом в последние годы пересматривают в сторону максимально возможно щадящего отношения к миндалинам лимфоглоточного кольца как важнейшему органу становления местного иммунитета в детском возрасте. Именно поэтому крайне актуальными остаются аспекты разработки эффективной консервативной терапии данной патологии и т.н. возрастного подхода к решению проблемы [15, 17, 18, 23, 25, 26].

В качестве одной из широко обсуждаемых возможных причин столь частой встречаемости патологии глоточной миндалины приводят ее бактериальную обсемененность $[15,26]$. Вместе с тем, по некоторым данным, различий в показателях обсемененности микробной флорой носоглотки больных и здоровых детей не существует [18]. Известно, что микробиологический состав носоглотки достаточно разнообразен, но какие именно возбудители могут иметь первостепенное значение в развитии аденоидита и гипертрофии глоточной миндалины - до сих пор однозначно не ясно [24]. В последние годы появляются сведения о доминирующей роли Haemophilus influenzae, Streptococcus pneumoniae, Moraxella catarrhalis в патогенезе гипертрофии и воспалительных изменений глоточной миндалины [13, 18, 24].

Анализ результатов микробиологических исследований свидетельствует, что у 63\% детей при аденоидных вегетациях присутствует патогенная флора [13, 15, $18,24,25]$. Приблизительно в 80\% случаев это кокки - Staphylococcus aureus, Staphylococcus epidermidis, Streptococcus pyogenes, Streptococcus pneumoniae, причем среди них превалирует S. aureus (до 73\%). Показано, что у детей с клиническими проявлениями гипертрофии глоточной миндалины без ее воспаления часто с поверхности высевается нормальная микрофлора (до $37 \%$ случаев), тогда как при наличии проявлений воспаления аденоидных вегетаций нормальная флора присутствует существенно реже: в среднем в 13,6\% $[13,15,17,18,24]$.

Основными признаками аденоидных вегетаций считаются частые и затяжные насморки (более чем в 90\% случаев), кашель и покашливание $(87,2 \%)$, храп (82,1\%), затруднение носового дыхания $(48,7 \%)$, отиты (25\%) $[17,18]$.

В план консервативной терапии аденоидитов с учетом признаваемой большинством исследователей бактериальной инвазии как важной причины данного заболевания обычно включают антимикробные средства $[13,15,18,23,25,26]$. Препараты местного действия могут назначать в виде монотерапии и как часть комбинированного лечения $[17,25,26]$. Как продемонстрировано в крупных отечественных исследованиях, в последние годы в качестве высокоэффективного, хорошо переносимого и безопасного местного антибактериального препарата для лечения аденоидитов хорошо зарекомендовал себя препарат Изофра. В результате его применения 
происходит значимое сокращение размеров аденоидных вегетаций за счет коррекции бактериального состава микрофлоры носоглотки [13, 16, 17].

Заболевания носа и околоносовых пазух (риниты, синуситы, риносинуситы) воспалительного характера острого и хронического течения занимают одно из первых мест в структуре ЛОР-патологии в детском возрасте: около $17-25 \%$ [6, 11, 12, 27]. Число больных закономерно увеличивается в осенне-зимний период, во время вспышек респираторных инфекций. В России за 2011 г. было зафиксировано около 93000 случаев острого риносинусита на 100 тыс. детей в возрасте до 14 лет [28].

Острый риносинусит - наиболее частое проявление острых вирусных инфекций у детей, причем его развитие типично для подавляющего числа вирусных возбудителей у детей любого возраста. Собственно изолированные формы ринита и синусита встречаются достаточно редко [9, 12, 19, 27, 29]. Существуют данные о том, что более чем в 85\% случаев к симптомам ринита у детей присоединяются признаки острого синусита уже через 2 сут от начала заболевания [27, 29].

Для риносинусита, вызваного вирусом гриппа, характерны носовые кровотечения, фаринголарингит, трахеит, лейкопения и моноцитоз (в отличие от бактериальной инфекции) [30]. Особенностью течения острого риносинусита у детей раннего и грудного возраста любой этиологии является внезапное начало, часто агрессивное, с высокой степенью интоксикации течение, широкое распространение воспалительного процесса с вероятностью перехода на близлежащие органы и ткани (орбиту, мозговые оболочки, клетчаточные пространства шеи, верхние дыхательные пути). У детей дошкольного возраста - частое рецидивирование, в подростковом возрасте характерно латентное течение заболевания $[2,11,29,30]$.

В первые 4 года жизни наиболее частая форма синуситов - этмоидиты (80-92\% всех случаев). К 4 годам окончательно формируются гайморовы пазухи, поэтому увеличивается удельный вес верхнечелюстных синуситов. В связи с более поздним формированием фронтальных и сфеноидальных синусов их воспаление наблюдается преимущественно у детей 7-12 лет, нередко встречается комбинированное поражение слизистой оболочки верхнечелюстных пазух и решетчатого лабиринта [7, 30-32].

Поскольку большинство заболеваний изначально имеет вирусную природу, потенциал применения антибактериальныхпрепаратов относительно невелик. Риносинусит бактериальной природы встречается у детей в 5-10\% случаев, чаще развиваясь как осложнение вирусной инфекции, которая благодаря отеку и инфильтрации слизистой оболочки полости носа, создавая обструкцию выводных отверстий синусов и нарушая функцию мерцательного эпителия, создает благоприятные условия для развития бактериальной суперинфекции [9, 12, 27].

Для острых риносинуситов более характерна монофлора, микробные ассоциации встречаются, по разным данным, в 10-30\% всех случаев [19, 29, 31, 32]. Основную роль в возникновении острого воспалительного процесса полости носа и околоносовых пазух в детском возрасте отводят S. pneumoniae (20-35\%) и H. influenzae (6-26\%). Причем более тяжелые случаи заболевания обычно связаны c S. pneumoniae. Реже причиной острого риносинусита являются M. catarrhalis (до 24\%), S. pyogenes (до 20\%), S. aureus (до 8\%). Роль грамотрицательных бактерий и анаэробов считается минимальной. S. pyogenes и S. aureus при риносинуситах чаще всего встречаются у детей старшего возраста. M. catarrhalis выделяют в основном у младшей возрастной группы [24, 30-34].

В последние годы значительно возросла роль синегнойной палочки и стафилококка в возникновении острых воспалительных процессов носоглотки. Риносинуситы, вызванные синегнойной палочкой и протеем, протекают тяжело, носят затяжной характер и чаще переходят в хроническую форму [13, 31].

В настоящее время общепринятой является классификация, выделяющая:

- острый синусит (длится < 3 мес);

- рецидивирующий острый синусит (2-4 случая острого синусита в год);

- хронический синусит (продолжительность симптомов $>3$ мес);

- обострение хронического синусита (усиление имеющихся и/или появление новых симптомов) [29].

Одна из важных причин хронизации риносинуситов сопутствующие аллергические реакции и заболевания. Кроме этого, длительное применение сосудосуживающих капель, гипертрофия аденоидов, искривленная носовая перегородка и другие анатомические нарушения полости носа, носовые полипы, одонтогенная инфекция, муковисцидоз, некоторые системные заболевания, протекающие с поражением мерцательного эпителия, также способствуют этому процессу $[11,12]$. Среди возбудителей хронических риносинуситов все большее значение приобретают анаэробы: их выделяют у 48\% пациентов (Prevotella spp. - 31\%, анаэробные стрептококки - 22\%, Fusobacterium spp. - 15\% и др.). Аэробные возбудители встречаются в 52\% случаев: стрептококки - 21\%, H. influenzae - 16\%, Pseudomonas aeruginosa - 15\%, S. aureus и M. catarrhalis - в 10\%. Микробные ассоциации обнаруживают приблизительно в 1/2 случаев [27, 30].

Большинство детей с острым риносинуситом проходят лечение в амбулаторных условиях, поэтому педиатру или лОР-врачу при первом визите заболевшего ребенка нужно решить нелегкую задачу: определить природу заболевания, от чего будет зависеть тактика его ведения и лечения. Отличительным диагностическим признаком бактериальных риносинуситов от ОРВИ, протекающей с риносинуситом, может являться длительность симптоматики (> 10 сут, но менее 12 нед) или же двухфазное течение с ухудшением через 5 и более сут. Для бактериальной инвазии характерно наличие гнойного секрета и болевого синдрома, особенно выраженного с одной стороны. Клиническое ухудшение после непродолжительного периода уменьшения степени выраженности симптоматики также характерно для начала бактериальных осложнений [27].

Часто ошибка заключается в профилактическом назначении антибиотика пациенту с ОРВИ в первые сутки манифестации риносинусита. При сохранении симптомов риносинусита более 7-10 сут у 60\% детей можно пред- 
полагать наличие бактериальной инфекции. Именно тогда в большинстве случаев целесообразно рассмотреть вопрос о назначении антибактериального препарата (вероятно, местного действия) [2, 27, 29]. Конечно же, основаниями для начала этиотропной терапии служат особенности течения заболевания и динамика клинических симптомов в каждом конкретном случае, поэтому не самолечение ребенка родителями, а обращение к специалисту с последующим врачебным наблюдением поможет избежать нежелательных осложнений.

Лечение хронических синуситов представляет собой достаточно трудную задачу, т. к. зачастую присутствующие в пазухах микроорганизмы устойчивы к антибактериальной терапии. С помощью противовоспалительной терапии и деконгестантов необходимо купировать длительно присутствующие, торпидно протекающие явления воспаления и отека слизистой оболочки [13, 30, 31].

Следовательно, антибактериальное топическое лечение в сочетании с назальными и/или системными противоотечными и противовоспалительными средствами, элиминационная терапия для удаления патологического секрета занимают основное место в лечении острого и обострении хронического риносинусита. Выбор комбинации этих средств зависит от клинической картины и тяжести заболевания в каждом конкретном случае.

Лекарственные препараты топического действия компании "Лаборатория Бушара-Рекордати" полностью отвечают необходимым требованиям к терапии детей с данной патологией $[13,16,21]$. В зависимости от клинической ситуации практикующий врач может выбрать соответствующий задачам лечения препарат. Многочисленные исследования отечественных педиатров и отоларингологов по применению анализируемых назальных спреев в случаях острых и хронических бактериальных воспалительных заболеваний полости носа, придаточных пазух и глоточной миндалины показали их высокую эффективность в отношении ускорения темпов выздоровления детей, купирования клинической симптоматики воспалительного процесса, в улучшении качества жизни маленьких пациентов с хроническими патологическими процессами $[13,16-18,20,25]$.

Частыми операционными вмешательствами у детей являются аденотомия, полипотомия полости носа, радикальные операции на околоносовых пазухах, подслизистая резекция перегородки носа и септопластика, операции на носовых раковинах, в т.ч. ультразвуковым и лазерным ножом, иссечение синехий полости носа, удаление новообразований полости носа [20]. В этих случаях воспалительная реакция в ответ на хирургическую травму, последствия хронического воспаления существенно повышают риск присоединения бактериальной инфекции. Выраженные отек слизистой оболочки, нарушение микроциркуляции, функциональная несостоятельность мукоцилиарного транспорта, а также скопление секрета в полости носа усугубляют воспаление, замедляют процессы регенерации, потенцируют активацию местной микрофлоры. Модификация этих патологических процессов с помощью местной медикаментозной терапии является залогом благоприятного течения послеоперационного периода. Применение топического антибакте-

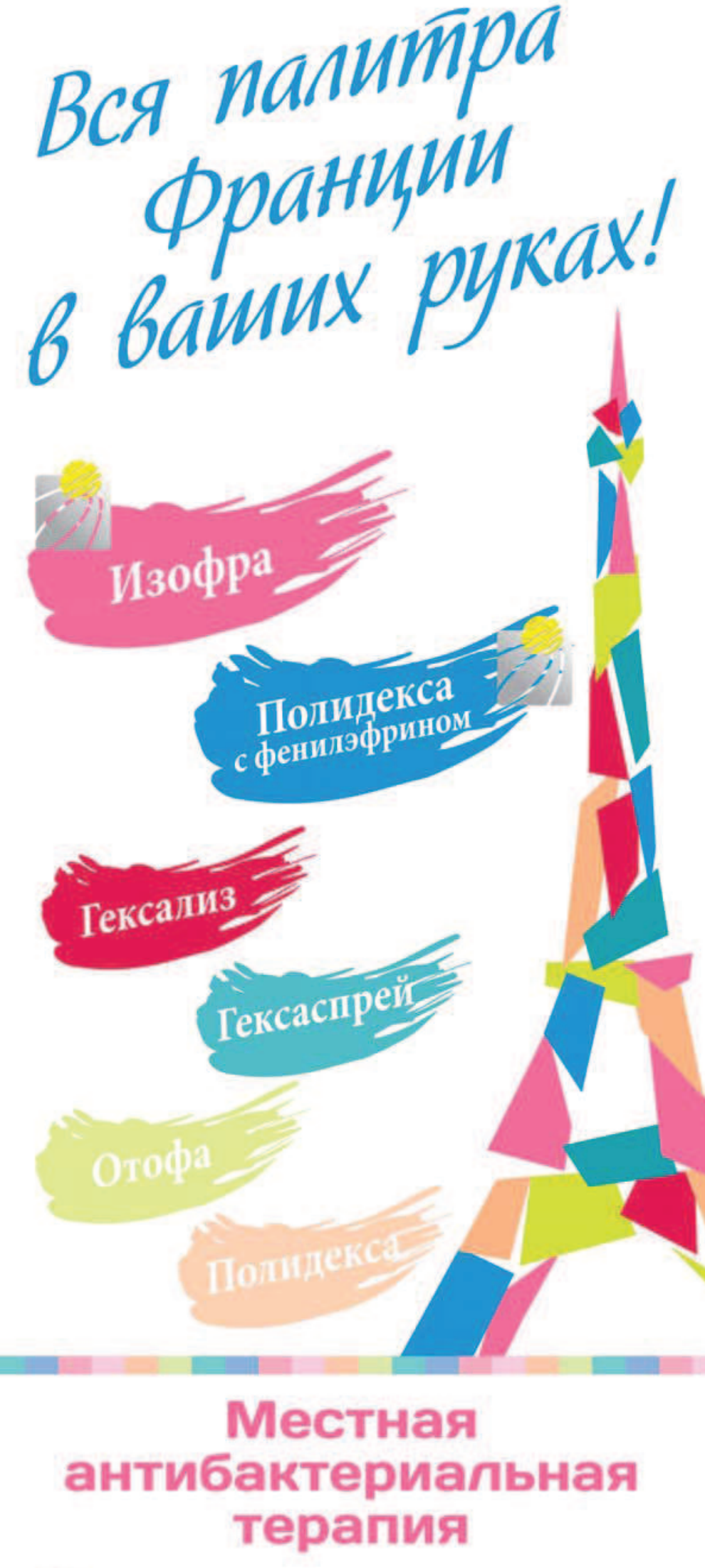

синуситов

ринитов

ринофарингитов аденоидитов

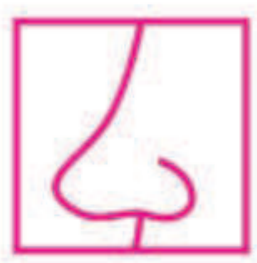

ООО «Русфик: 123610, Москва, Краснопресненская на6., А. 12, офис 747 Ten. (495) 2582006 , факс (495) 2582007 
риального препарата комплексного действия в таких случаях, по результатам проведенных наблюдений, является крайне привлекательным. После аденотомий целесообразно также ограничиться монопрепаратом антибактериального действия [20-21].

Таким образом, при лечении воспалительной патологии носоглотки и околоносовых пазух бактериальной природы в детском возрасте в большинстве случаев целесообразно прибегать к местной антибактериальной терапии как обоснованной альтернативе системному применению антибиотиков. Решение о назначении этиотропного лечения должно быть строго взвешенным. Описанные в статье антибактериальные препараты топического действия обладают доказанным высо- ким профилем безопасности для применения в детском возрасте. Изофра не имеет возрастных ограничений в использовании, Полидекса с фениэфрином разрешена к применению детям с 2,5 лет [21]. Указанные препараты могут быть рекомендованы к использованию в случаях воспалительных бактериальных заболеваний полости носа и околоносовых пазух, в послеоперационном периоде для профилактики осложнений. По данным клинических исследований, Изофра эффективно сокращает размер аденоидных вегетаций и особенно показана при аденоидитах $[13,21]$. Уникальный состав Полидексы с фенилэфрином делает ее препаратом первой линии при хронических воспалительных процессах в носоглотке.

\section{СПИСОК ЛИТЕРАТУРЫ}

1. Острые респираторные заболевания у детей: лечение и профилактика. Научно-практическая программа Союза педиатров России под ред. акад. РАМН А. А. Баранова. М. 2002.

2. Таточенко В.К. Терапия ОРЗ у детей. РМЖ. 2004; 21: 21-24.

3. Зубков М.Н. Алгоритм терапии острых и хронических инфекций верхних и нижних дыхательных путей. РМЖ. 2009; 17 (2): 123-131. 4. Respiratory tract infections - antibiotic prescribing. Prescribing of antibiotics for self-limiting respiratory tract infections in adults and children in primary care. Clin. Guidelines, 2008; 69.

5. Маркова Т.П., Чувиров Д.Г. Лечение и профилактика воспалительных заболеваний слизистой оболочки полости рта и глотки у детей. М. 2002. С. 52-59.

6. Борзов Е.В. Распространенность патологии лоР-органов у детей. Новости оториноларингол. и логопатол. 2002; 1 (29): 3-8.

7. Пронина Ю.В., Вахрушев С.Г., Буренков Г.И., Зырянов М.М. Распространенность сочетанной патологии полости носа и носоглотки у детей. Росс. ринология. 2003; 3: 56.

8. Страчунский Л. С., Белоусов Ю.Б., Козлов С.Н. Антибактериальная терапия: Практ. рук-во. М. 2003. 42 с.

9. Benhaberou-Brun D. Acute rhinosinusitis. Are antibiotics necessary? Perspect. Infirm. 2009; 6 (3): 37-38.

10. Calus L., Van Zele T., Derycke L., Krysko O. Local inflammation in chronic upper airway disease. Curr. Pharm. Des. 2012; 18 (16): 2336-2346.

11. Poachanukoon O., Nanthapisal S., Chaumrattanakul U. Pediatric acute and chronic rhinosinusitis: comparison of clinical characteristics and outcome of treatment. Asian Pac. J. Allerg. Immunol. 2012; 30 (2): 146-151.

12. Fokkens W. J., Lund V. J., Mullol J., Bachert C. European position paper on rhinosinusitis and nasal polyps 2012. Rhinol. Suppl. 2012; 23 (3): 1-298.

13. Балясинская Г.Л., Богомильский М.Р. Применение топических антибактериальных препаратов в терапии воспалительных заболеваний полости носа, носоглотки и околоносовых пазух у детей. Росс. вестн. перинатол. и педиатрии. 2003; 2: 48-53.

14. Хаитов Р.М. Практическое пособие по клинической иммунологии и аллергологии. М.: Торус Пресс. 2005. 187 с.

15. Меркулова Е.П., Баранаева Е.А., Пивоварова Н. П., Прокофьева Н.А. Реальные и потенциальные надежды лечения аденоидов у детей. Медицинские новости. 2010; 10: 87-90.

16. Рязанцев С.В. Отофа, Изофра и Полидекса - новые препараты для лечения отитов и риносинуситов. Новости оториноларингол. и логопатол. 2001; 115-116.

17. Батчаев А. С. Сравнительный анализ клинической эффективности различных методов лечения хронических аденоидитов. Новости оториноларингол. и логопатол. 2002; 1 (29): 43-45.

18. Радциг Е. Ю. Новые возможности местной терапии аденоидитов у детей. Лечащий врач. 2006; 6: 17-21.

19. Гучев И.А., Колосов А.А. Рациональная антибактериальная терапия острой инфекции верхних дыхательных путей (риносинусит). Лечащий врач. 2007; 9: 33-36.

20. Свистушкин В. М., Овчинников А. Ю., Никифорова Г.Н. Воспаление после операций в полости носа и околоносовых пазухах: необходимость медикаментозного регулирования. Росс. ринол. 2007; 2: 56-61.

21. Федеральное руководство для врачей по использованию лекарственных средств (формулярная система): вып. III. М.: ГЭОТАР-Медиа. 2002. 462 с.

22. Brandtzaeg $P$. Immune function of nasopharyngeal lymphoid tissue. The 7th International Symposium on Tonsils and Mucosal Barriers of the Upper Airways. 2010; 67.

23. Belluci L. Clinical guideline on adenotonsillectomie in Italy. The 7th International Symposium on Tonsils and Mucosal Barriers of the Upper Airways. 2010; 91.

24. Жуховицкий В.Г. Бактериологическое обоснование рациональной антибактериальной терапии в оториноларингологии. Вестн. оториноларингол. 2004; 1: 5-15.

25. Козлов В.С., Карпов В.А. Роль местной терапии в лечении хронического аденоидита. РМЖ. 2002; 20, 23-27.

26. Brook I. Effects of antimicrobial therapy on the microbial flora of the adenoids. J. Antimicrob. Chemother. 2003; 51 (6): 1331-1337. 27. Лопатин А. С., Гамов В.П. Острый и хронический риносинусит: этиология, патогенез, клиника, диагностика и принципы лечения. М. 2011. 58 с.

28. Инфекционная заболеваемость в РФ за 2011 г. Детские инфекции. 2012; 1: 5-7.

29. Лопатин А. С., Свистушкин В. М. Острый риносинусит: этиология, патогенез, диагностика и принципы лечения. М.: Российское общество ринологов. 25 с.

30. Белобородова Н. В., Окатовская А. Б., Гаращенко Т. И. Эффективность новой двукратной формы амоксициллина/клавуланата при риносинуситах у детей. Consilium medicum (Приложение "Педиатрия"). 2005; 7 (1): 31-36.

31. Богомильский М.Р. Основные принципы лечения синуситов у детей. Лечащий врач. 2001; 8: 22-27.

32. Yoshimura K., Kawata R., Haruna S., Moriyama H. Clinical epidemiological study of 553 patients with chronic rhinosinusitis in Japan. Allergol. Int. 2011; 60 (4): 491-496.

33. Wood A. J., Fraser J.D., Swift S., Patterson-Emanuelson E. A. Intramucosal bacterial microcolonies exist in chronic rhinosinusitis without inducing a local immune response. Am. J. Rhinol. Allergy. 2012; 26 (4): 265-270.

34. McCoul E. D., Jourdy D. N., Schaberg M.R., Anand V.K. Methicillin-resistant Staphylococcus aureus sinusitis in nonhospitalized patients: A systematic review of prevalence and treatment outcomes. Laryngoscope. 2012; 122 (10): 2125-2131. 